\title{
LESSON 97
}

MARGINS: Pica, 20-70; Elite, Type each line 3 times paying attention to good typing technique. $30-80$.

Clinic

Revise 'an' words

If you find that you make mistakes when typing words with the 'an' combination, try this exercise.

Revise Punctuation

Revise Numbers

Revise the space bar

Bounce your right thumb off the space bar as you type these lines.

Increase Speed

30 wpm 6 minutes.

$\mathrm{S} 38-\mathrm{SI} 1.04$

Can you remember?
1. an and ant van ran hand band tank thank rank drank

2. can man any fan pans land many wand tanner spanner

3. Andy handed another spanner to an older handy man.

4. "Please," said Mary, "bring us four more lunches."

5. "Catch it," yelled Hugh, "it hit his bat high up."

6. "Can you come over on Sunday for tea?" asked Jean.

7. The 45 boys and 67 girls spent $£ 538.29$ on holiday.

8. The crowd of 47,921 paid $£ 51,132.59$ to see it win.

9. His Mark 12 car did 104.73 miles in just one hour.

10. bar my may not far ink new set day oil nut yes due

11. gun no hut ear pun see may tin ore set try nil rot

12. and to the may day lot say fly pat vat tap ask mix

If you have a garden, do you grow your plants from seed or do you buy them from the shops? Most plants can be grown from seed, and seeds cost much less than plants. All you need, is a few trays in which to set the seeds and some compost. Read the notes on the seed packets to see when to set them, and take note of how deep they are to be set. All you have to do then is to keep the soil moist, put the trays in a warm place and wait. Some seeds do not take long to come up but others may take quite a long time.

Once the plants start to grow you must keep a close check on how much light and warmth they get, and see that the soil does not dry out. Thin them out as soon as you can and make sure that they get all the room to grow in they need. If you let too many stop in a tray they will grow too tall and be of no use to you. You will soon find that you can raise all the plants you will need for quite a low cost.

\begin{tabular}{|l|l|l|l|l|l|l|l|l|l|l|l|l|} 
& 1 & 2 & 2 & 3 & 4 & 5 & 6 & 7 & 7 & 8
\end{tabular}

Can you remember what the following abbreviations stand for? Type the answers.

$\begin{array}{llrlllll}\text { 1. } & \text { f.o.b. } & 6 . & \text { B.O.A.C. } & 11 . & \text { B.R. } & 16 . & \text { V.A.T. } \\ \text { 2. } & \text { E.E.C. } & 7 . & \text { B.A. } & 12 . & \text { B.R.S. } & 17 . & \text { p.p. } \\ \text { 3. } & \text { T.U.C. } & 8 . & \text { C.S.E. } & 13 . & \text { O.B.E. } & 18 . & \text { Ed. } \\ \text { 4. } & \text { O.H.M.S. } & 9 . & \text { B.B.C. } & 14 . & \text { s.a.e. } & 19 . & \text { a/c } \\ \text { 5. } & \text { C.O.D. } & 10 . & \text { Co-op } & 15 . & \text { S.R.N. } & 20 . & \text { etc. }\end{array}$

UNIT 25/CONSOLIDATION LESSON 97 